\title{
Problematic internet use and its association with sleep disturbance and life satisfaction among Palestinians during the COVID-19 pandemic
}

\author{
Fayez Azez Mahamid ${ }^{1}$ (D) Denise Ziya Berte ${ }^{2} \cdot$ Dana Bdier $^{1}$ \\ Accepted: 14 July 2021 / Published online: 24 July 2021 \\ (C) The Author(s), under exclusive licence to Springer Science+Business Media, LLC, part of Springer Nature 2021
}

\begin{abstract}
The current study was conducted to test the relationship between problematic internet use, sleep disturbance, and life satisfaction among Palestinians during the Covid-19 pandemic. The sample consisted of 366 Palestinian adults (129 males and 237 females), recruited from online advertisements, e-mail campaigns, social media, and SMS campaigns. Results of the correlational analysis showed that problematic internet use positively correlated with sleep disturbance $(\mathrm{r}=.19, p<.01)$, and negatively correlated with life satisfaction $(\mathrm{r}=-.17, p<.01)$. Moreover, life satisfaction negatively correlated to sleep disturbance $(\mathrm{r}=-.25, p<.01)$. The regression analysis for predicting problematic internet use found that life satisfaction contributes in a way that was statistically significant towards explaining variance in problematic Internet use $(\mathrm{B}=-.15, \mathrm{SE}=.05, \beta=-.15)$, in addition sleep disturbance explained statistically and significantly variance in problematic internet use $(\mathrm{B}=.16, \mathrm{SE}=.04, \beta=.20)$. Intervention programs directed at decreasing internet use may need to be updated to better address the issues of "necessary" excessive use during COVID-19 restrictions and re-entry into normalized activity patterns when shut-downs are finished. As a completely new area of investigation, this study can serve as an impetus to further examinations of these important topics.
\end{abstract}

Keywords Problematic internet use $\cdot$ Life satisfaction $\cdot$ Sleep disturbance $\cdot$ Covid-19 $\cdot$ Palestine

\section{Introduction}

An acute respiratory disease caused by Coronavirus 2 commonly called COVID-19, was declared a pandemic on March 11, 2020 by the WHO (World Health Organization), (Abebe et al., 2020; Mahamid \& Bdier, 2020a). By 29 June 2021 there were 180.492. 131 confirmed cases of COVID-19, including 3. 916. 771 deaths around the world (World Health Organization, 2021a). 343.251 confirmed cases of COVID-19 with 3.838 deaths have been registered in the

Fayez Azez Mahamid

mahamid@najah.edu

Denise Ziya Berte

deniseziyaberte@icloud.com

Dana Bdier

danamm37@hotmail.com

1 Psychology and Counseling Department, An-Najah National University, Nablus, Palestine

2 Nationalities Service Center, Philadelphia, USA occupied Palestinian territories (World Health Organization, 2021b).

COVID-19 disease is characterized medically by pneumonia, lymphopenia, exhausted lymphocytes and a cytokine storm (Cao, 2020). However apart from the physical impact of COVID-19 on affected victims, the experience of living in a pandemic has been found to be associated with several psychological impairments among individuals in the general population including depression, anxiety, and symptoms related to post-traumatic stress disorder (PTSD) (Guessoum et al., 2020; Liang et al., 2020; Mahamid \& Bdier, 2021; Mahamid, Veronese, \& Bdier, 2021b).

As restrictions on travel and social activity were enacted the use of the internet exponentially increased globally as the computer became the primary workplace, school, social and leisure space for the population (Power et al., 2020; Prakash et al., 2020). Additionally, with medical centers focused on infected patients, the internet became the main source of medical information about the new epidemic for the general population (Hashemi et al., 2020). Internet social networking sites have additionally served as a way to reduce the stress and anxiety related to fear of COVID-19 disease (Király et al., 2020). 
Problematic internet use (PIU) could be characterized by an individual's inability to control their internet use, which in turn leads to mental health problems, decreased work productivity, strained relationships and functional impairment of daily activities (Liu \& Potenza, 2007; Shapira et al., 2003). Liu et al. (2011) defined PIU as uncontrolled use of the internet that leads to significant psychosocial and functional impairments, and this pattern of use is not better accounted for by a primary psychiatric disorder such as mania or the physiological effects of a substance.

The prevalence of PIU among individuals in Taiwan was found to increase to $24.4 \%$ of the population during the COVID-19 outbreak (Lin, 2020). In Indonesia daily online duration increased by $52 \%$ as compared to before the pandemic, the point prevalence of problematic internet use found to be $14.4 \%$ (Siste et al., 2020). In the general Mexican population, it was found that $62.7 \%$ of the population had some degree of problematic internet use (Garcia-Priego et al., 2020).

PIU is expected to be a serious behavioral problem among Palestinians during COVID-19 epidemic, as in addition to stressors related COVID-19 disease, the population is exposed to multiple environmental stressors (i.e. economic, social, and political) as a product of occupation (Mahamid \& Bdier, 2021) including poverty, unemployment, restrictions on movement, militarization and the psychological impacts of military occupation (Berte et al., 2021; Mahamid \& Berte, 2019; Mahamid \& Berte, 2020).

From a theoretical perspective PIU may be a result of both distal and proximal causes. Distal causes may include preexisting psychopathology (e.g., social anxiety and depression) and behavioral reinforcement (e.g., provided by the internet itself through rewarding cues that reinforce conditioned responses), (Agbaria \& Bdier, 2019). Proximal causes may involve maladaptive cognitions that reinforce one's motivation to engage in compulsive internet use (Griffiths et al., 2016).

PIU or internet addiction is considered to be part of the compulsive-impulsive spectrum disorders, where the individual experiences a loss of control over their internet use and continues to engage with the internet excessively despite experiencing negative consequences (Agbaria \& Bdier, 2020). There are several models proposed to explain the mechanism s that may cause PIU and Internet addiction. Cognitive-behavioral models of PIU focus on the maladaptive cognitions among individuals that lead to Internet addiction. Individuals with PIU may believe they are incapable of forming a relationship or attaining a career, leading them to search for success in a virtual world which is less complicated, unilateral, and provides immediate and continual feedback (Davis, 2001).

According to social-cognition theory, the expected positive social outcomes of use such as increasing valued social contacts and social reinforces (such as "likes") create a propensity to excessive use and addiction(Larose et al., 2001). There is also an operant learning aspect of internet use where the positive effect caused by positive virtual feedback is paired with use and reinforces increased use especially for those who have little social positive interaction in their normal lives due to social isolation, timidity, or decreased communication skills (Murali \& George, 2007).

Throughout the COVID-19 pandemic, problematic internet use has been found to be a risk factor for different mental health issues including symptoms of depression, and anxiety (Dong et al., 2020; Duan et al., 2020). PIU has also been found to be positively associated with higher rates of sleep disorders among Bangladeshi nationals during COVID-19 pandemic (Islam et al., 2020).

Sleep-wake disorders or sleep disturbances are defined as changes in sleep- wake patterns or rhythms that may include problems with the quality, timing, and amount of sleep, which can result in daytime distress (i.e. physical and psychological distress) and impairment in social, occupational, or other areas of functioning (Ouellet et al., 2015). According to the Diagnostic and Statistical Manual of Mental Disorders (DSM-5), sleep-wake disorders encompass 10 distinct sleep patterns including: insomnia, hypersomnolence, narcolepsy, breathing-related sleep disorders, circadian rhythm sleep disorders, non-REM (NREM) sleep arousal disorders, nightmare disorder, REM sleep behavior disorder, restless leg syndrome, and substance- or medication-induced sleep disorder (APA, 2015).

Primary sleep disorders are those not associated with a medical condition, substance use or concurrent psychological disorder, in which the first line treatment is characterized by psychological and behavioral interventions such as sleep hygiene, sleep restriction, stimulus control, relaxation training and cognitive therapy, while pharmacological treatments are considered as the second choice (Ferracioli-Oda et al., 2013).

During the COVID-19 pandemic a major portion of the global population has noted an increase in the development of sleep disorders. For example, high rates of sleep disorders were detected in the Moroccan population during COVID-19 pandemic compared to previous rates (Idrissi et al., 2020). While among a mixed sample population from India, USA, UK, UAE, Canada, Singapore, Australia, Germany, Kuwait, Oman, Qatar, and Saudi Arabia, COVID-19 was lockdown found to be associated with changes in sleep schedule as well as the quantity and quality of night-time sleep, including shifts to a later bedtime and waking time, a reduction in night-time sleep and an increase in day-time napping (Gupta et al., 2020). The relationship between COVID-19 and severe sleep disorders was also noted among the French population, especially young people (Beck et al., 2020).

In the area of excessive technology use, Fernandes et al. (2020) found that individuals from India, Malaysia, Mexico and the UK, who scored highly on gaming addiction, compulsive internet use and social media use reported high scores on 
a scale of poor sleep quality. Moreover, working from home or doing online classes during COVID-19 restrictions has been identified as a potential predictive factor for sleep disturbance (Ara et al., 2020). Results of a cross sectional study revealed that internet gaming disorder directly positively influenced insomnia among Iranian adolescents during COVID19 shutdowns (Fazeli et al., 2020).

While problematic internet use found to be a risk factor for several mental health issues during the COVID-19 epidemic (Dong et al., 2020; Duan et al., 2020; Islam et al., 2020), high levels of life satisfaction is predicted to be a protective factor against problematic internet use at all times, but increasingly so during the epidemic, as individuals satisfied with their lives are characterized as having high levels of self-esteem, self-efficacy, social skills, social awareness, and social support (Burger \& Samuel, 2017; Ma, 2020; Moksnes \& Espnes, 2013; Rezaei \& Jeddi, 2020). Moreover, individuals with high levels of life satisfaction have been found to exhibit lesser problematic behaviors (Sun \& Shek, 2012). Given the previous research has shown that high levels of life satisfaction are correlated with multiple positive psychological factors, it is likely that life satisfaction would be a protective factor against problematic internet use during COVID-19 epidemic as well.

Results of recent studies are consistent in regard to the association between PIU and life satisfaction. Longstreet and Brooks (2017) found that greater life satisfaction is associated with decreased internet and social media addiction. In the USA, internet addiction was associated with lower life satisfaction (Błachnio et al., 2019). Furthermore, higher ranges of internet use disorder have been associated with lower scores of life satisfaction in China and Germany (Lachmann et al., 2018). In addition, a significant negative correlation was noted between problematic internet use and life satisfaction among university students (Çelik \& Odac1, 2013). Among Palestinian, video game addiction scores, during COVID-19, were negatively associated with life satisfaction (Mahamid \& Bdier, 2020b).

\section{Current Study}

The current study was designed to examine the association between problematic internet use, sleep disturbance, and life satisfaction among Palestinians during the COVID-19 pandemic. Based on previous research findings, the current study hypothesizes that 1) problematic internet use is positively correlated with sleep disturbance among Palestinians during the COVID-19 pandemic, 2) and life satisfaction is negatively correlated with problematic internet use among Palestinians during the COVID-19 pandemic.

\section{Methodology}

\section{Participants}

Participants were recruited from online advertisements, e-mail campaigns, social media, and SMS campaigns; Participants were 366 Palestinian adults (129 males and 237 females). 60.7 of participants had a graduate degree, 35.2 had a Bachelor degree, and 4.1 with a high school degree. A geographical representation of the participants showed that $61.5 \%$ of participants were from cities. $35.2 \%$ were from villages, and $3.3 \%$ were from internally displaced refugee camps. Inclusion in the study required participants to be: 1) Palestinian, 2) native Arabic speakers 3) free from having been diagnosed with any form of neurodevelopmental or mental health impairment. The study was submitted for review by An-Najah Institutional Review Board (IRB) and received approval before data collection was initiated. Informed consent was obtained electronically before data were collected from the participants.

\section{Instruments and Procedures}

The Problematic Internet Usage Scale (IDS9-SF) The IDS9-SF is one of the most robust psychometric screening tools for assessing problematic internet use developed by Pontes and Griffiths (2016). The scale is comprised of nine questions regarding problematic internet use (e.g., "Have you jeopardized or lost an important relationship, career or an educational opportunity because of your online usage?") which are responded to on a five-point Likert scale ranging from 1 (Never) to 5 (Very often). Total scores are obtained by summing the raw scores of each item. Total scores range from 9 to 45 , with higher scores indicating a higher degree of problematic internet use. In the present study, the Cronbach's alpha of IDS9-SF indicated very good internal consistency $(\alpha=.85)$.

The Satisfaction with Life Scale (SWL) The scale was prepared by Diener et al. (1985) and measures subjective satisfaction with life on five items using multiple-choice options. The items on the scale include the following: I1. For most things, my life is close to my ideal; I2. The conditions of my life are excellent; I3. I am satisfied with my life; I4. So far, I have gotten the things that are important to me in life; and I5. If I were born again, I would change almost nothing in my life. The original SWL scale includes seven multiple-choice answers ranging from: " 1 = Strongly disagree" to " $5=$ Strongly agree". In the present study, the Cronbach's alpha of IDS9-SF indicated very good internal consistency $(\alpha=.87)$.

The DSM-5 Level 2-Sleep Disturbance Scale Adult Measure is an 8-item short form that assesses the domain of sleep 
disturbance in individuals age 18 and older. The measure is completed by the individual. Each item on the measure is rated on a 5 -point scale $(1=$ never; $2=$ rarely; $3=$ sometimes; $4=$ often; and $5=$ always) with a range in score from 8 to 40 with higher scores indicating greater severity of sleep disturbance. The raw scores of the 8 items are summed to obtain a total raw score. In the present study, the Cronbach's alpha of IDS9-SF indicated very good internal consistency $(\alpha=.93)$.

\section{Research Procedures}

The data for this study was conducted in April 2021 and targeted Palestinians living in the West Bank of Palestine. The sample was recruited online using convenience sampling techniques; all participants were provided with information that enabled them to make an informed decision as to whether or not they wanted to participate in the research. They were provided with descriptions of the scales and the purpose of the research. Participants who agreed to participate in the research signed a formed consent. The research was conducted in line with the ethical guidelines of the American Psychological Association (APA, 2010) and the Declaration of Helsinki (1964), and had been approved by the An- Najah National University IRB.

\section{Data Analysis}

To examine the degree of Problematic Internet Usage, Life Satisfaction and Sleep Disturbance among Palestinian adults during the COVID-19 pandemic; means, standard deviations, range, Kurtosis and Skewness were used. Pearson's correlation coefficient was also conducted to test the correlation between study variables; Problematic internet usage, life satisfaction and sleep disturbance. The Pearson correlation coefficient, also known as the sample correlation coefficient (r), product-moment correlation coefficient, or coefficient of correlation, measures and interprets the linear relationship between two or more random variables (Zou et al., 2003). The regression analysis was also performed to test the relationship between problematic Internet usage, life satisfaction and sleep disturbance; the purpose of regression analysis was to evaluate the relative impact of a predictor variable on a particular outcome (Zou \& Hall, 2002).

\section{Findings}

As Table 1 indicates, overall the participants scored on mild level of problematic internet use, with high scores on life satisfaction and moderate scores on sleep disturbance.

As shown in Table 2, Problematic Internet Usage was negatively correlated with life satisfaction, and positively correlated with sleep disturbance, while life satisfaction was negatively correlated with sleep disturbance.

Results of Table 2 showed a statistically significant negative correlation between problematic Internet usage and life satisfaction $(\mathrm{r}=-.17, p<.01)$, the regression analysis for predicting problematic internet usage (Table 3 ) found that life satisfaction contributes in a way that was statistically significant towards explaining variance in problematic Internet usage $(\mathrm{B}=-.15, \mathrm{SE}=.05, \beta=-.15)$.

Results of Table 2 also showed a statistically significant positive correlation between problematic Internet usage and sleep disturbance $(\mathrm{r}=.19, p<.01)$. The regression analysis for predicting problematic Internet usage (Table 3 ) found that Sleep disturbance contributed in a way that was statistically significant towards explaining variance in problematic Internet usage $(\mathrm{B}=.16, \mathrm{SE}=.04, \beta=.20)$. Finally, a statistically significant negative correlation (Table 2 ) found between life satisfaction and sleep disturbance $(\mathrm{r}=-.25, \mathrm{p}<.01)$.

\section{Discussion}

The current study demonstrates, as in previous investigations across cultures, a strong relationship between problematic internet use patterns and sleep disturbance as well as a consistent negative relationship between positive life satisfaction and problematic internet use in a sample of adults in Palestine during the COVID-19 epidemic. General findings indicate that the sample exhibited moderate levels of sleep disturbances, minimal levels of problematic internet use and high levels of life satisfaction which were unexpected general findings given the level of stress of individuals living both under occupation and during a pandemic with inadequacies in medical testing, protective gear and treatment options.

There are some unique findings such as the high levels of life satisfaction and minimal levels of problematic internet use which are in opposition to previous studies (Mahmid \& Berte, 2019). These results may be due to the internal limitations of the data. The sample was highly educated and nonrepresentative of the general population (over $60 \%$ had graduate degrees). All three measures are based on self-report with subjective responses without ties to specific behavioral indicators which may increase the effect of positive self-presentation. Self-report measures often inflate scores of life satisfaction and decrease scores of problematic internet use depending on the cultural norms of the population. This positive self-bias may be compounded by the education level and age of the participants who may be more motivated to present themselves in a positive light. In addition, a COVID-19 environment was the context of the study but not a variable that was studied or measured in any unique as a variable; correlations between indicated variables were simply investigated during the COVID-19 pandemic in Palestine. 
Table 1 Descriptive statistics for research variables $(N=366)$

\begin{tabular}{|c|c|c|c|c|c|c|c|c|}
\hline Variable & Mean & S.D & Min & Max & Range & Kurtosis & Skewness & Reliability \\
\hline Problematic Internet usage & 2.520 & .765 & 1.11 & 4.56 & 3.44 & -.128 & .596 & .859 \\
\hline Life satisfaction & 3.527 & .768 & 1.00 & 5.00 & 4.00 & .953 & -.787 & .876 \\
\hline Sleep disturbance & 3.102 & .991 & 1.00 & 5.00 & 400 & -.605 & .228 & .932 \\
\hline
\end{tabular}

The clearest findings of the study, which indicate a positive relationship between excessive internet use and sleep disorders and a negative relationship between excessive internet use and life satisfaction. These findings are in correspondence with global finding which pair problematic internet use with a multitude of psychological risks (such as sleep disorders) and as negatively predicting life satisfaction in the Palestinian population (Mahamid \& Berte, 2020).

Managing internet use during a pandemic and in a politically unstable militarized zone where work, education, socialization and leisure are tied to an on-line presence may prove to be challenging. Internet use is now needed for individuals to participate in life sustaining activities such as employment, education, medical consultations, therapeutic groups, family communication and so much more. In addition the nonproductive activities such as gaming, social media, and watching random videos may have indirect positive effects of reducing stress, adding distraction, and reducing interpersonal conflicts offering a social outlet unattached to shared residents. There is no way to easily distinguish between use that is necessary and tied to productive activity and the neurological effects of overuse will be differentiable between productive vs non-productive use.

The fear of COVID-19 in a powerful factor related to emotional health in Palestine currently (Mahamid, Bdier, \& Berte, 2021a). The fear of COVID-19 in Palestine is complex and tied to the realities of occupation as the infection itself is regulated by transportation between the territories and the occupying force as well as the access to protective gear, testing, treatment and vaccines. There are serious concerns about underlying agendas of the occupying forces who are both considered the highest risk for admitting the virus the virus to the occupied territories and the provider of testing, PPI and vaccines.

Table 2 Correlations among study variables $(\mathrm{N}=366)$

\begin{tabular}{llll}
\hline Measures & $(1)$ & $(2)$ & $(3)$ \\
\hline (1) Problematic Internet usage & - & $-.176^{* *}$ & $.199 * *$ \\
(2) Life satisfaction & & - & $-.251^{* *}$ \\
(3) Sleep disturbance & & & - \\
\hline
\end{tabular}

$* * p<0.01$
Sleep disorders in general have increased globally related to sleep disorders and may be a confounding factor in this investigation. Centralized nervous system activation is a biological inevitability in situations where individuals have a valid threat of death and/or destruction of their wellbeing via a loss of employment, illness of a loved one, inability to access needed resources. All of these factors are part of the COVID19 environment and would likely cause an increase in sleeping disorders apart from excessive internet use.

\section{Conclusion}

Intervention programs directed at decreasing internet use may need to be updated to better address the issues of "necessary" excessive use during COVID-19 restrictions and re-entry into normalized activity patterns when shut-downs are done. Very little is yet known about the effects of productive but excessive internet use and its impact including decreased exercise, increased multi-tasking, changed sleep/ wake patterns, etc. As few communities have lifted all COVID-19 restrictions, it is also unclear what symptom trajectories will occur when individuals return to normal activities. Intervention programs addressing the fear of leaving the home, being with other people, returning to employment sites, separating from family members, etc. will all need to be explored as different communities lift COVID-19 restrictions.

In addition few treatment options are available for sleep disturbances in most developing nations aside from chemical agents to enhance sleep. Most interventions for sleep disorders are based on assumptions that individuals live in safe environments, where being prepared for emergency events is not a regular need, which may not be best practice for individuals in

Table 3 Regression to problematic internet usage $(\mathrm{N}=366)$

\begin{tabular}{lllllll}
\hline Variable & $\mathrm{B}$ & $\mathrm{SE}$ & $B$ & $\mathrm{~T}$ & $\mathrm{p}$ & $95 \% \mathrm{CL}$ \\
\hline Life satisfaction & -.158 & .054 & -.159 & -2.932 & $.004 * *$ & {$[-.26--.05]$} \\
Sleep disturbance & .160 & .042 & .208 & 3.858 & $.000^{* * *}$ & {$[.07-.24]$} \\
Gender & -.123 & .078 & -.082 & -1.635 & .070 & {$[-.44--.10]$} \\
Residence & -.119 & .068 & -.071 & -1.550 & .999 & {$[-.25-.03]$} \\
Educational level & -.129 & .073 & -.084 & -1.684 & .074 & {$[-.26-2.49]$} \\
\hline
\end{tabular}

$* * p<0.01, * * p<0.001$ 
highly conflictual geo-political areas. The specific mechanisms that sustain sleep and are interrupted by excessive internet use must be identified and remediated for an intervention to be effective in any environment. In addition underlying personality, environmental and physiological links between sleeping disorders and excessive internet use must be explored to create best practice models to address this relationship. As a completely new area of investigation, this study can serve as an impetus to further examinations of these important topics.

Acknowledgement The datasets generated during and/or analysed during the current study are available from the corresponding author on reasonable request.

\section{Declarations}

Ethical Approval All procedures performed in this study involving human participants were in accordance with the ethical standards of AnNajah University's Research Ethics Board, the American Psychological Association (APA, 2010) and with the 2013 Helsinki Declaration.

Informed Consent Informed consent was obtained from all participants.

Conflict of Interest The authors declare that they have no conflict of interest. No funding was received for this study.

\section{References}

Abebe, E. C., Dejenie, T. A., Shiferaw, M. Y., \& Malik, T. (2020). The newly emerged COVID-19 disease: A systemic review. Virology Journal, 17(1), 1-8. https://doi.org/10.1186/s12985-020-01363-5.

Agbaria, Q., \& Bdier, D. (2019). The association of big five personality traits and religiosity on internet addiction among Israeli-Palestinian Muslim college students in Israel. Mental Health, Religion \& Culture, 22(9), 956-971. https://doi.org/10.1080/13674676.2019. 1699041.

Agbaria, Q., \& Bdier, D. (2020). The role of social support and subjective well-being as predictors of internet addiction among IsraeliPalestinian college students in Israel. International Journal of Mental Health and Addiction. . Advance online publication. https://doi.org/10.1007/s11469-020-00282-4.

American Psychiatric Association. (2015). Sleep-wake disorders: DSM$5 \circledast$ selections. American Psychiatric Pub.

APA. (2010). Ethical principles of psychologists and code of conduct. The American Psychologist, 65, 493. https://doi.org/10.1037/ a0020168

Ara, T., Rahman, M., Hossain, M., \& Ahmed, A. (2020). Identifying the associated risk factors of sleep disturbance during the COVID-19 lockdown in Bangladesh: A web-based survey. Frontiers in Psychiatry, 11, 966. https://doi.org/10.3389/fpsyt.2020.580268.

Beck, F., Léger, D., Fressard, L., Peretti-Watel, P., Verger, P., \& Coconel Group. (2020). Covid-19 health crisis and lockdown associated with high level of sleep complaints and hypnotic uptake at the population level. Journal of Sleep Research, e13119. Advance online publication. https://doi.org/10.1111/jsr.13119.

Berte, D. Z., Mahamid, F. A., \& Affouneh, S. (2021). Internet addiction and perceived self-efficacy among university students. International Journal of Mental Health and Addiction, 19, 162-176. https://doi. org/10.1007/s11469-019-00160-8.
Błachnio, A., Przepiorka, A., Benvenuti, M., Mazzoni, E., \& Seidman, G. (2019). Relations between facebook intrusion, internet addiction, life satisfaction, and self-esteem: A study in Italy and the USA. International Journal of Mental Health and Addiction, 17(4), 793 805. https://doi.org/10.1007/s11469-018-0038-y.

Burger, K., \& Samuel, R. (2017). The role of perceived stress and selfefficacy in young people's life satisfaction: A longitudinal study. Journal of Youth and Adolescence, 46(1), 78-90. https://doi.org/ 10.1007/s10964-016-0608-x.

Cao, X. (2020). COVID-19: Immunopathology and its implications for therapy. Nature Reviews Immunology, 20(5), 269-270. https://doi. org/10.1038/s41577-020-0308-3.

Çelik, Ç. B., \& Odacı, H. (2013). The relationship between problematic internet use and interpersonal cognitive distortions and life satisfaction in university students. Children and Youth Services Review, 35(3), 505-508. https://doi.org/10.1016/j.childyouth.2013.01.001.

Davis, R. (2001). A cognitive-behavioral model of pathological internet use. Computers in Human Behavior, 17, 187-195. https://doi.org/ 10.1007/s11469-017-9870-8

Declaration, H. (1964). Adopted by the 18th World Medical Assembly, Helsinki, Finland, June 1964. Amended by the 29th World Medical Assembly Tokyo, Japan, October, 197.

Diener, E., Emmons, R. A., Larsen, R. J., \& Griffin, S. (1985). The satisfaction with life scale. Journal of Personality Assessment, 49, 71-75. https://doi.org/10.1207/s15327752jpa4901_13.

Dong, H., Yang, F., Lu, X., \& Hao, W. (2020). Internet addiction and related psychological factors among children and adolescents in China during the coronavirus disease 2019 (COVID-19) epidemic. Frontiers in Psychiatry, 11, 751-800. https://doi.org/10.3389/fpsyt. 2020.00751.

Duan, L., Shao, X., Wang, Y., Huang, Y., Miao, J., Yang, X., \& Zhu, G. (2020). An investigation of mental health status of children and adolescents in China during the outbreak of COVID-19. Journal of Affective Disorders, 275, 112-118. https://doi.org/10.1016/j.jad. 2020.06.029.

Fazeli, S., Zeidi, I. M., Lin, C. Y., Namdar, P., Griffiths, M. D., Ahorsu, D. K., \& Pakpour, A. H. (2020). Depression, anxiety, and stress mediate the associations between internet gaming disorder, insomnia, and quality of life during the COVID-19 outbreak. Addictive Behaviors Reports, 12, 100307. https://doi.org/10.1016/j.abrep. 2020.100307.

Fernandes, B., Biswas, U. N., Mansukhani, R. T., Casarín, A. V., \& Essau, C. A. (2020). The impact of COVID-19 lockdown on internet use and escapism in adolescents. Revista de Psicología Clínica con Niños y Adolescentes, 7(3), 59-65 https://dialnet.unirioja.es/servlet/ articulo? codigo $=7649333$.

Ferracioli-Oda, E., Qawasmi, A., \& Bloch, M. H. (2013). Meta-analysis: Melatonin for the treatment of primary sleep disorders. PLoS One, 8(5), e63773. https://doi.org/10.1371/journal.pone.0063773.

Garcia-Priego, B. A., Triana-Romero, A., Pinto-Galvez, S. M., DuranRamos, C., Salas-Nolasco, O., Reyes, M. M., et al. (2020). Anxiety, depression, attitudes, and internet addiction during the initial phase of the 2019 coronavirus disease (COVID-19) epidemic: A crosssectional study in Mexico. medRxiv. Advance online publication. https://doi.org/10.1101/2020.05.10.20095844.

Griffiths, M. D., Kuss, D. J., Billieux, J., \& Pontes, H. M. (2016). The evolution of internet addiction: A global perspective. Addictive Behaviors, 53, 193-195. https://doi.org/10.1016/j.addbeh.2015.11. 001.

Guessoum, S. B., Lachal, J., Radjack, R., Carretier, E., Minassian, S., Benoit, L., \& Moro, M. R. (2020). Adolescent psychiatric disorders during the COVID-19 pandemic and lockdown. Psychiatry Research, 291, 113264. https://doi.org/10.1016/j.psychres.2020. 113264.

Gupta, R., Grover, S., Basu, A., Krishnan, V., Tripathi, A., Subramanyam, A., Nischal, A., Hussain, A., Mehra, A., Ambekar, 
A., Saha, G., Mishra, K. K., Bathla, M., Jagiwala, M., Manjunatha, N., Nebhinani, N., Gaur, N., Kumar, N., Dalal, P. K., Kumar, P., Midha, P. K., Daga, R., Tikka, S. K., Praharaj, S. K., Goyal, S. K., Kanchan, S., Sarkar, S., Das, S., Sarkhel, S., Padhy, S. K., Sahoo, S., Satyanarayana Rao, T. S., Dubey, V., Menon, V., Chhabra, V., Lahan, V., \& Avasthi, A. (2020). Changes in sleep pattern and sleep quality during COVID-19 lockdown. Indian Journal of Psychiatry, 62(4), 370-378. https://doi.org/10.4103/psychiatry. IndianJPsychiatry_523_20.

Hashemi, S. G. S., Hosseinnezhad, S., Dini, S., Griffiths, M. D., Lin, C. Y., \& Pakpour, A. H. (2020). The mediating effect of the cyberchondria and anxiety sensitivity in the association between problematic internet use, metacognition beliefs, and fear of COVID-19 among Iranian online population. Heliyon, 6(10), e05135. https://doi.org/10.1016/j.heliyon.2020.e05135.

Idrissi, A. J., Lamkaddem, A., Benouajjit, A., El Bouaazzaoui, M. B., El Houari, F., Alami, M., et al. (2020). Sleep quality and mental health in the context of COVID-19 pandemic and lockdown in Morocco. Sleep Medicine, 74, 248-253. https://doi.org/10.1016/j.sleep.2020. 07.045 .

Islam, M. S., Sujan, M. S. H., Tasnim, R., Ferdous, M. Z., Masud, J. H. B., Kundu, S., Mosaddek, A. S. M., Choudhuri, M. S. K., Kircaburun, K., \& Griffiths, M. D. (2020). Problematic internet use among young and adult population in Bangladesh: Correlates with lifestyle and online activities during the COVID-19 pandemic. Addictive Behaviors Reports, 12, 100311. https://doi.org/10.1016/j. abrep.2020.100311.

Király, O., Potenza, M. N., Stein, D. J., King, D. L., Hodgins, D. C., Saunders, J. B., Griffiths, M. D., Gjoneska, B., Billieux, J., Brand, M., Abbott, M. W., Chamberlain, S. R., Corazza, O., Burkauskas, J., Sales, C. M. D., Montag, C., Lochner, C., Grünblatt, E., Wegmann, E., Martinotti, G., Lee, H. K., Rumpf, H. J., Castro-Calvo, J., Rahimi-Movaghar, A., Higuchi, S., Menchon, J. M., Zohar, J., Pellegrini, L., Walitza, S., Fineberg, N. A., \& Demetrovics, Z. (2020). Preventing problematic internet use during the COVID-19 pandemic: Consensus guidance. Comprehensive Psychiatry, 100, 152180. https://doi.org/10.1016/j.comppsych.2020.152180.

Lachmann, B., Sindermann, C., Sariyska, R. Y., Luo, R., Melchers, M. C., Becker, B., Cooper, A. J., \& Montag, C. (2018). The role of empathy and life satisfaction in internet and smartphone use disorder. Frontiers in Psychology, 9, 398. https://doi.org/10.3389/fpsyg. 2018.00398.

Larose, R., Mastro, D., \& Eastin, M. S. (2001). Understanding Internet Usage. Social Science Computer Review, 19(4), 395-413. https:// doi.org/10.1177/089443930101900401.

Liang, L., Ren, H., Cao, R., Hu, Y., Qin, Z., Li, C., \& Mei, S. (2020). The effect of COVID-19 on youth mental health. Psychiatric Quarterly, 91, 841-852. https://doi.org/10.1007/s11126-020-09744-3.

Lin, M. P. (2020). Prevalence of internet addiction during the covid-19 outbreak and its risk factors among junior high school students in Taiwan. International Journal of Environmental Research and Public Health, 17(22), 8547. https://doi.org/10.3390/ ijerph17228547.

Liu, T., \& Potenza, M. N. (2007). Problematic internet use: Clinical implications. CNS Spectrums, 12(06), 453-466. https://doi.org/10. 1017/s1092852900015339.

Liu, T. C., Desai, R. A., Krishnan-Sarin, S., Cavallo, D. A., \& Potenza, M. N. (2011). Problematic Internet Use and Health in Adolescents. The Journal of Clinical Psychiatry, 72(06), 836-845. https://doi. org/10.4088/jcp. $10 \mathrm{~m} 06057$

Longstreet, P., \& Brooks, S. (2017). Life satisfaction: A key to managing internet \& social media addiction. Technology in Society, 50, 73-77. https://doi.org/10.1016/j.techsoc.2017.05.003.

Ma, C. M. (2020). The relationship between social support and life satisfaction among Chinese and ethnic minority adolescents in Hong Kong: The mediating role of positive youth development. Child
Indicators Research, 13(2), 659-679. https://doi.org/10.1007/ s12187-019-09638-2.

Mahamid, F. A., \& Bdier, D. (2020a). Fear of COVID-19 and mental health outcomes among psychosocial service providers in Palestine: The mediating role of well-being. Journal of Concurrent Disorders, 3(1), 45-60. Retrieved April 08, 2021, fromhttps:// concurrentdisorders.ca/2021/04/08/fear-of-covid-19-and-mentalhealth-outcomes-among-psychosocial-service-providersinpalestine-the-mediating-role-of-well-being-2/

Mahamid, F. A., \& Bdier, D. (2020b). Aggressiveness and life satisfaction as predictors for video game addiction among Palestinian adolescents. Journal of Concurrent Disorders, 3(2), 45-53. Retrieved April 25, 2021, from https://concurrentdisorders.ca/2021/04/25/ aggressiveness-and-life-satisfaction-as-predictors-for-video-gameaddiction-among-palestinianadolescents-2/

Mahamid, F. A., \& Bdier, D. (2021). The association between positive religious coping, perceived stress, and depressive symptoms during the spread of coronavirus (COVID-19) among a sample of adults in Palestine: Across sectional study. Journal of Religion and Health, 60, 34-49. https://doi.org/10.1007/s10943-020-01121-5.

Mahamid, F. A., Bdier, D., \& Berte, D. Z. (2021a). Psychometric properties of the Fear of COVID-19 Scale (FCV-19S) in a Palestinian context. Manuscript submitted for publication.

Mahamid, F. A., \& Berte, D. Z. (2020). Portrayals of violence and at-risk populations: Symptoms of trauma in adolescents with high utilization of social media. International Journal of Mental Health and Addiction, 18, 980-992. https://doi.org/10.1007/s11469-018-99990 .

Mahamid, F. A., \& Berte, D. Z. (2019). Social media addiction in geopolitically at-risk youth. International Journal of Mental Health and Addiction, 17(1), 102-111. https://doi.org/10.1007/s11469-0179870-8.

Mahamid, F., Veronese, G., \& Bdier, D. (2021b). Fear of coronavirus COVID19 and mental health outcomes in Palestine: The mediating role of social support. Manuscript submitted for publication.

Moksnes, U. K., \& Espnes, G. A. (2013). Self-esteem and life satisfaction in adolescents - Gender and age as potential moderators. Quality of Life Research, 22(10), 2921-2928. https://doi.org/10.1007/s11136013-0427-4.

Murali, V., \& George, S. (2007). Lost online: an overview of internet addiction. Advances in Psychiatric Treatment, 13(1), 24-30. https:// doi.org/10.1192/apt.bp.106.002907

Ouellet, M. C., Beaulieu-Bonneau, S., \& Morin, C. M. (2015). Sleepwake disturbances after traumatic brain injury. The Lancet Neurology, 14(7), 746-757. https://doi.org/10.1016/S14744422(15)00068-X.

Pontes, H. M., \& Griffiths, M. D. (2016). The development and psychometric properties of the internet disorder scale-short form (IDS9SF). Addicta: The Turkish Journal on Addictions, 3(3), 303-318. https://doi.org/10.15805/addicta.2016.3.0102.

Power, E., Hughes, S., Cotter, D., \& Cannon, M. (2020). Youth mental health in the time of COVID-19. Irish Journal of Psychological Medicine, 37(4), 301-305. https://doi.org/10.1017/ipm.2020.84.

Prakash, S., Yadav, J. S., \& Singh, T. B. (2020). An online cross-sectional study to assess the prevalence of internet addiction among people staying at their home during lockdown due to COVID-19. International Journal of Indian Psychology, 8(3), 424-432. https:// doi.org/10.25215/0803.052.

Rezaei, A., \& Jeddi, E. M. (2020). Relationship between wisdom, perceived control of internal states, perceived stress, social intelligence, information processing styles and life satisfaction among college students. Current Psychology, 39(3), 927-933. https://doi.org/10. 1007/s12144-018-9804-z.

Shapira, N. A., Lessig, M. C., Goldsmith, T. D., Szabo, S. T., Lazoritz, M., Gold, M. S., \& Stein, D. J. (2003). Problematic internet use: 
Proposed classification and diagnostic criteria. Depression and Anxiety, 17(4), 207-216. https://doi.org/10.1002/da.10094.

Siste, K., Hanafi, E., Lee Thung Sen, H. C., Adrian, L. P. S., Limawan, A. P., Murtani, B. J., \& Suwartono, C. (2020). The impact of physical distancing and associated factors towards internet addiction among adults in Indonesia during COVID-19 pandemic: A nationwide web-based study. Frontiers in Psychiatry, 11, 580977. https://doi. org/10.3389/fpsyt.2020.580977.

Sun, R. C., \& Shek, D. T. (2012). Positive youth development, life satisfaction and problem behaviour among Chinese adolescents in Hong Kong: A replication. Social Indicators Research, 105(3), 541-559. https://doi.org/10.1007/s11205-011-9786-9.

World Health Organization. (2020a). Weekly epidemiological update on COVID-19 - 29 June 2021. Retrived June 29, 2021 from https:// www.who.int/publications/m/item/weekly-epidemiological-updateon-covid-19-29-june-2021

World Health Organization. (2021b). Occupied Palestinian territory, including east Jerusalem. Retreived June 29, 2021, from https:// covid19.who.int/region/emro/country/ps

Zou, K. H., \& Hall, W. J. (2002). On estimating a transformation correlation coefficient. Journal of Applied Statistics, 29(5), 745-760. https://doi.org/10.1080/02664760120098801.

Zou, K. H., Tuncali, K., \& Silverman, S. G. (2003). Correlation and simple linear regression. Radiology, 227(3), 617-628. https://doi. org/10.1148/radiol.2273011499.

Publisher's Note Springer Nature remains neutral with regard to jurisdictional claims in published maps and institutional affiliations. 